\title{
Reduced Mortality of Staphylococcus aureus Bacteremia in a Retrospective Cohort Study of 2139 Patients: 2007-2015
}

\author{
Eloise D. Austin, ${ }^{1}$ Sean S. Sullivan, ${ }^{1}$ Nenad Macesic, ${ }^{1,2}$ Monica Mehta, ${ }^{3}$ Benjamin A. Miko, ${ }^{1}$ Saman Nematollahi, ${ }^{4}$ Oiuhu Shi, ${ }^{5}$ Franklin D. Lowy, ${ }^{1,6}$ and \\ Anne-Catrin Uhlemann ${ }^{1,7}$
}

${ }^{1}$ Department of Medicine, Division of Infectious Diseases, Columbia University Irving Medical Center, New York, New York; ${ }^{2}$ Department of Infectious Diseases, Austin Hospital, Heidelberg, Victoria, Australia; ${ }^{3}$ Department of Pharmacy, New York Presbyterian Hospital, New York; ${ }^{4}$ Department of Medicine, Division of Infectious Diseases, Johns Hopkins University School of Medicine, Baltimore, Maryland; ${ }^{5}$ Department of Public Health, School of Health Sciences and Practice, New York Medical College, Valhalla; ${ }^{6}$ Department of Pathology and Cell Biology, Clinical Microbiology Laboratory, Columbia University Medical Center, New York, New York; and ${ }^{7}$ Department of Medicine Microbiome \& Pathogen Genomics Core, Columbia University Medical Center, New York, New York

Background. Understanding the changing epidemiology of Staphylococcus aureus bacteremia, as well as the variables associated with poor outcomes, can yield insight into potential interventions.

Methods. This study was a retrospective, observational cohort study of adult patients at an academic medical center in New York City who had S. aureus bloodstream infections between 1 January 2007 and 31 December 2015. Participants were divided into 3 periods: group 1 (2007-2009), group 2 (2010-2012), and group 3 (2013-2015) for trend analysis. All clinical strains were genotyped (spa.). The main outcome was 30 -day all-cause mortality.

Results. There were 1264 episodes of methicillin-susceptible S. aureus (MSSA) and 875 episodes of methicillin-resistant S. aureus (MRSA) bacteremia, with a rising proportion due to MSSA (55\% group 1; 59\% group 2; 63\% group 3; $P=.03$.) There were no significant changes in average age, gender, Charlson score, and distribution of strain genotypes. Mortality in MRSA infection was unchanged (25\% group 1;25\% group 2; 26\% group 3), while mortality in MSSA infection significantly declined (18\% group 1;18\% group 2; 13\% group 3). The average time to antistaphylococcal therapy (AST) in MSSA infection declined during the study (3.7 days group $1 ; 3.5$ group $2 ; 2.2$ group 3). In multivariate analysis, AST within 7 days of initial positive MSSA culture was associated with survival.

Conclusions. Mortality in MSSA bloodstream infection is declining, associated with a decrease in time to targeted therapy. These results emphasize the potential for rapid diagnostics and early optimization of treatment to impact outcomes in MSSA bacteremia.

Keywords. Staphylococcus aureus; MRSA; MSSA; bacteremia.

Staphylococcus aureus bacteremia (SAB) is the source of significant morbidity worldwide, with 30 -day mortality ranging from $15 \%$ to $40 \%$ even with effective antibiotic therapy [1-3]. Understanding large-scale epidemiologic trends in clinical characteristics and outcomes is important for designing prevention measures and treatment protocols. Additionally, inclusion of not only clinical but also genotypic and phenotypic data into epidemiologic studies can provide a clearer picture of the relative contributions of host, pathogen, and environment $[4,5]$.

Trends in the incidence of $\mathrm{SAB}$ over the past decade have varied by region and clinical setting [6-9]. Compared with methicillin-susceptible $S$. aureus (MSSA), invasive infections with methicillin-resistant $S$. aureus (MRSA) have traditionally been associated with higher mortality, complication rates,

Received 22 January 2019; editorial decision 29 May 2019; accepted 10 June 2019; published online June 11, 2019.

Correspondence: A.-C. Uhlemann, Division of Infectious Diseases, Department of Medicine, 630 West 168th Street, Box 82, New York, NY 10032 (au2110@cumc.columbia.edu).

Clinical Infectious Diseases ${ }^{\circledR} \quad$ 2020;70(8):1666-74

(C) The Author(s) 2019. Published by Oxford University Press for the Infectious Diseases Society of America. All rights reserved. For permissions, e-mail: journals.permissions@oup.com. DOI: $10.1093 / \mathrm{cid} / \mathrm{ciz} 498$ and hospital length of stay $[1,10]$, although some studies have failed to detect mortality differences after adjustment for confounding factors [11]. However, while MRSA bacteremia receives greater attention in research aimed at prevention and treatment, MSSA accounts for a larger portion of SAB cases at many centers and therefore should be a major focus of efforts to improve SAB outcomes $[8,12]$. Similarly, while MRSA has often been considered as the dominant cause of hospitalacquired S. aureus infections, recent studies have suggested a potential shift in characteristics of MSSA bloodstream infection (BSI) toward a more healthcare-associated clinical profile, as the relative frequency of community-associated MRSA has increased $[6,7,13]$.

A major aim of epidemiologic surveys that look at characteristics of SAB is to develop tools for predicting mortality and to identify modifiable factors, such as diagnostic and treatment interventions, that can become targets for intervention. Prior studies have shown an association between increased age, comorbidity burden, and individual comorbid diseases on mortality in SAB $[14,15]$. A recent large retrospective study also suggested female gender to be a risk factor for mortality in community-associated SAB, although the underlying

1666 • CID 2020:70 (15 April) • Austin et al 
mechanism for this association remains poorly understood $[16,17]$.

Fewer studies have examined mortality trends in the context of bacterial genotypes that, along with the antimicrobial susceptibility phenotype, are increasingly being included in analyses of SAB $[7,18]$. An examination of temporal trends in SAB clinical outcomes must include the context of host factors, bacterial genotype, and treatment practices, since shifts in any of these areas can impact outcomes.

In this study, we determined whether there were significant changes in mortality in SAB cases over a 9-year period and whether there were corresponding changes in genotypic and clinical factors in these SAB cases. We then looked at the contribution of molecular and clinical variables to mortality.

\section{METHODS}

\section{Population and Study Design}

This was a retrospective, observational cohort study of all adult patients aged $\geq 18$ years at a large tertiary care medical center in New York City who had $\geq 1$ blood culture positive for $S$. aureus between 1 January 2007 and 31 December 2015. Only the first episode of BSI per patient in a given year was included. The participants were divided into cohorts based on 3-year time periods: group 1 (2007-2009), group 2 (2010-2012), and group 3 (2013-2015). Patients with S. aureus bacteremia were identified through a query of the electronic medical record (EMR) system performed by the Clinical Data Warehouse Navigator. The Columbia University Irving Medical Center (CUIMC) Institutional Review Board approved this study. Demographic and clinical data were extracted from the EMR, and research staff entered these data into a database. Data on age, gender, hospital admission, and discharge; subsequent positive blood cultures; antibiotic treatment; antimicrobial susceptibilities; and infectious diseases (ID) consultation were extracted from the EMR. ID consultation was defined as a formal consultation documented in the chart within 14 days of the index culture or primary medical management by an ID specialist. ID consultation data were not available for 20072009 and were analyzed only for the $2010-2015$ period. Data on comorbidities were extracted from the EMR through a query of International Classification of Diseases, Ninth Revision, Clinical Modification, and International Classification of Diseases, Tenth Revision, Clinical Modification, codes corresponding to the comorbidity categories.

\section{Genotyping and Antibiotic Susceptibility}

Antibiotic susceptibility and minimum inhibitory concentrations (MICs) were determined using the automated MicroScan method, based on Clinical and Laboratory Standards Institute standards [19]. To perform molecular typing, we sequenced the repeat region of the staphylococcal protein A $(s p a)$ gene and assigned spa type using the SpaType
RIDOM software [20]. Distribution of genotype into clonal lineages was determined using the Based Upon Repeat Pattern clustering algorithm [21].

\section{Definitions}

Mortality was determined through extraction of CUIMC EMR mortality data, manual review of charts, and query of the Social Security Administration Master Death File. Duration of bacteremia was determined based on the number of days with positive blood cultures; instances where the patient died on the same day of the index blood culture were excluded from duration analysis. Bloodstream infections were considered to be "community-onset" (CO) if the positive index culture was collected $\leq 48$ hours of presentation. Infections with index cultures collected $>48$ hours from time of admission were given the designation "hospital-onset" (HO).

\section{Outcomes}

The primary outcome was 30-day all-cause mortality.

\section{Statistical Analyses}

All statistical analyses were performed using SAS v9.4 (SAS Institute, Inc). The Cochran-Armitage trend test was used to test the mortality significance of trends over the 3 time periods. The $\chi^{2}$ test or analysis of variance was used to examine univariate associations depending on categorical or continuous variables. Univariate logistic regression was used to examine the association between the mortality outcome and each covariate or factor. The multivariate logistic regression model included age and gender variables a priori and variables with univariate $P$ value $<.2$. Odds ratios with 95\% confidence intervals are presented.

\section{RESULTS}

\section{Overall Study Population}

Overall, there were 1264 episodes of MSSA and 875 episodes of MRSA BSI during the 2007-2015 study period. The incidence of MSSA infection was 2.2 cases per 1000 admissions and the incidence of MRSA infection was 1.52 cases per 1000 admissions during the study. Demographic variables, including average age ( $60 \pm 18$ vs $63 \pm 18$ years), were similar between MSSA and MRSA cohorts (Table 1). The majority of patients in both MSSA and MRSA cohorts were male $(n=775 / 1264,61 \%$ vs $n=518 / 875,59 \%)$, and $71 \%(n=898)$ of the MSSA and $68 \%$ $(n=592)$ of the MRSA infections were CO.

Patients with MSSA and MRSA differed in a number of important clinical variables. The average hospitalization length was longer for MRSA patients (25 days \pm 17 vs 22 days \pm 24 days). The average Charlson comorbidity score was higher for the MRSA infections (4.1) than for MSSA infections (3.6), as was the proportion of patients with a Charlson score $\geq 3$ (69\% of MRSA; $61 \%$ of MSSA). The average Pitt bacteremia 


\begin{tabular}{|c|c|c|c|}
\hline & $\begin{array}{l}\text { All Staphylococcus aureus Bloodstream } \\
\text { Infections }\end{array}$ & $\begin{array}{l}\text { Methicillin-susceptible } \\
\text { Staphylococcus aureus }\end{array}$ & $\begin{array}{l}\text { Methicillin-resistant } \\
\text { Staphylococcus aureus }\end{array}$ \\
\hline Variable & $\begin{array}{c}(N=2139) \\
n(\%)\end{array}$ & $\begin{array}{l}(n=1264) \\
n(\%)\end{array}$ & $\begin{array}{c}(n=875) \\
n(\%)\end{array}$ \\
\hline Average age (median), y & $61(62)$ & $60(61)$ & $63(63)$ \\
\hline Age $>65 y$ & $903(42)$ & $506(40)$ & $397(45)$ \\
\hline Male gender & $1293(60)$ & $775(61)$ & $518(59)$ \\
\hline Hospital-onset ( $\geq 48$ hours) & $649(30)$ & $366(29)$ & $283(32)$ \\
\hline Community-onset ( $\leq 48$ hours) & $1490(70)$ & $898(71)$ & $592(68)$ \\
\hline Infectious disease consultation & $874(61)^{\mathrm{a}}$ & $525(61)^{a}$ & $349(63)^{\mathrm{a}}$ \\
\hline PBS & $2.1(1)$ & $1.8(1)$ & $2.6(2)$ \\
\hline $\mathrm{PBS} \geq 4$ & $430(20)$ & $198(16)$ & $232(26)$ \\
\hline \multicolumn{4}{|l|}{ Comorbidity burden } \\
\hline Charlson score, average (median) & $3.8(4)$ & $3.6(3)$ & $4.1(4)$ \\
\hline Charlson score $\geq 3$ & $1373(64)$ & $770(61)$ & $603(69)$ \\
\hline Diabetes & $226(11)$ & $133(11)$ & $93(11)$ \\
\hline Prior myocardial infarct & $61(2.9)$ & $33(2.6)$ & $28(3.2)$ \\
\hline Peripheral vascular disease & $188(8.9)$ & $91(7.2)$ & $97(11)$ \\
\hline Chronic heart failure & $292(14)$ & $178(14)$ & $114(13)$ \\
\hline Chronic kidney disease & 537 (25) & $294(23)$ & $243(28)$ \\
\hline End-stage renal disease/dialysis & $256(12)$ & $136(11)$ & $120(14)$ \\
\hline Liver disease & $174(8.1)$ & $102(8.1)$ & $72(8.2)$ \\
\hline Chronic pulmonary disease & 199 (9.3) & $94(7.4)$ & $105(12)$ \\
\hline Malignancy & $229(11)$ & $154(12)$ & $75(8.6)$ \\
\hline Connective tissue disease & $6(0.2)$ & $4(0.3)$ & $2(0.2)$ \\
\hline HIV & $137(6.4)$ & $59(4.7)$ & $78(8.9)$ \\
\hline HIV/AIDS & $121(5.6)$ & $51(4.0)$ & $70(8)$ \\
\hline $\begin{array}{l}\text { Prior transient ischemic attack/cerebrovascular } \\
\text { accident }\end{array}$ & $47(2.2)$ & $20(1.6)$ & $27(3.1)$ \\
\hline Dementia & $123(5.7)$ & $68(5.4)$ & $55(6.3)$ \\
\hline Chemotherapy & $180(8.4)$ & $124(9.8)$ & $56(6.4)$ \\
\hline \multicolumn{4}{|l|}{ Duration of bacteremia } \\
\hline$\geq 3$ days & $631(29)$ & $358(28)$ & $273(31)$ \\
\hline$\geq 5$ days & $283(13)$ & $137(11)$ & 146 (17) \\
\hline$\geq 10$ days & $58(2.7)$ & $20(1.6)$ & $38(4.4)$ \\
\hline Admission days, average (median) & $23(15)$ & $22(15)$ & $25(16)$ \\
\hline \multicolumn{4}{|l|}{ Antibiotic susceptibility } \\
\hline $\begin{array}{l}\text { Vancomycin minimum inhibitory } \\
\text { concentration } \geq 1.5\end{array}$ & $918(43)$ & $540(43)$ & 378 (43) \\
\hline \multicolumn{4}{|l|}{ Genotype } \\
\hline spa-type & $\ldots$ & $\ldots$ & $\cdots$ \\
\hline t002 & $400(19)$ & $121(9.6)$ & 279 (32) \\
\hline t008 & $326(15)$ & $64(5.1)$ & $262(30)$ \\
\hline spa-CC group & $\ldots$ & $\ldots$ & \\
\hline spa-CC002/ST5 & $548(26)$ & $198(16)$ & $350(40)$ \\
\hline spa-CC008/ST8 & $560(26)$ & $177(14)$ & $383(44)$ \\
\hline
\end{tabular}

Abbreviations: CC, clonal complex; HIV, human immunodeficiency virus; PBS, Pitt bacteremia score.

aData for infectious disease consultation missing for 2007-2009 period.

score (PBS) and the proportion of patients with a PBS $\geq 4$ was higher in the MRSA than the MSSA cohort (2.6 vs 1.8 ; $26 \%$ vs $16 \%$ ). The average duration of bacteremia was longer for the MRSA cohort $(2.7 \pm 3.1$ days vs $2.2 \pm 2.4$ days $)$, and there were more patients in the MRSA cohort with bacteremia $\geq 3$ days $(\mathrm{n}=273 / 875,31 \%$ vs $\mathrm{n}=344 / 1264,28 \%)$. There were also more patients with persistent bacteremia ( $\geq 5$ days) in the
MRSA $(n=146,17 \%)$ than in the MSSA cohort $(n=137,11 \%)$. During the 2010-2015 period for which there was available consultation data, ID consultation took place for $61 \%$ of SAB patients overall, with $61 \%$ of MSSA and $63 \%$ of MRSA patients receiving consults. The 30-day mortality for the overall cohort was higher for MRSA $(221 / 875,25 \%)$ than for MSSA infections (203/1264, 16\%). 
Genotyping of the MSSA cohort showed a highly diverse genetic background, with 370 spa types, whereas spa types t002 and t008 accounted for nearly two-thirds of isolates in MRSA SAB. spa clonal complex CC002 (ST5) and spa-CC008 were the most frequent clonal cohorts seen in both MSSA ( $\mathrm{n}=198,16 \%$ spa-CC002; $\mathrm{n}=177,14 \%$ spa-CC008) and MRSA ( $\mathrm{n}=350,40 \%$ spa-CC002; $\mathrm{n}=383,44 \%$ spa-CC008) infections.

\section{Time-trend Analyses}

The incidence of MSSA BSI rose during the study (2.1 per 1000 admissions, $\mathrm{n}=396 /$ group $1 ; 2.0$ per 1000 admissions, $\mathrm{n}=402$ / group 2; 2.5 per 1000 admissions, $n=467 /$ group 3 ), and the incidence of MRSA BSI decreased (1.7 per 1000 admissions, $\mathrm{n}=318 /$ group $1 ; 1.4$ per 1000 admissions, $\mathrm{n}=276 /$ group $2 ; 1.5$ per 1000 admissions, $\mathrm{n}=281$ /group 3 ).

There were no significant changes in average age or gender during the study, either in the overall cohort or individually for MRSA and MSSA cohorts (Tables 2, 3). However, the proportion of patients aged $\geq 65$ years increased in the overall cohort ( $40 \%$ in group 1 to $46 \%$ in group $3, P=.01$ ). This was driven by an increase in patients aged $\geq 65$ years with MSSA infections (36\% in group 1 to $45 \%$ in group $3, P=.01$; Table 2 ). There was no significant change in the proportion of $\mathrm{HO}$ vs $\mathrm{CO}$ infections over the 3 periods. SAB with duration $\geq 3$ days, $\geq 5$ days, and $\geq 10$ days increased in frequency across the study period for both MSSA and MRSA (Table 2). Comparing frequency of ID consultation in group 2 vs group 3 (data for G1 was not available), using $\chi^{2}$ analysis, there was a significant increase in ID consultation in the overall SAB cohort (59\% to 64\%) and MRSA group ( $58 \%$ to $67 \%$ ); however, there was no significant change in the MSSA group (59\% to $62 \%$ ).

The average PBS overall and for MRSA SAB did not change significantly during the study; however, the average PBS for MSSA SAB increased (1.5 in group 1, 2.1 in group 2, 1.8 in group $3, P=.02)$, as did the proportion of patients with PBS $\geq 4(12 \%$ in group 1 to $16 \%$ in group $3, P=.02$ ). The Charlson scores did not change significantly for either the MSSA or MRSA cohorts (Table 2).

The distribution of bacterial genotypes across the CC cohorts remained stable, with CC002 (group 1, 25\%; group 3, 26\%) and CC008 (group 1, 25\%; group 3, 27\%) remaining the most frequently represented CCs. The proportion of isolates with vancomycin MIC $\geq 1.5$ increased significantly for both MRSA and MSSA cohorts across the 9-year period (group 1, 36\%; group 3, $61 \%$ ), and fluoroquinolone resistance decreased (group 1, 47\%; group 3, 39\%; Table 3).

The time to first dose of targeted antistaphylococcal therapy (AST) for MSSA (cefazolin or oxacillin, based on hospital practice in MSSA treatment) decreased significantly, with the average number of days before AST declining from 3.7 days during 2007-2009 and 3.5 days during 2010-2012 to 2.2 days during 2013-2015 $(P<.0001$; Table 3$)$. The proportion of patients receiving a first dose of cefazolin or oxacillin within 3 days of positive culture increased from $42 \%(n=167)$ in group 1 and $46 \%(n=186)$ in group 2 to $62 \%(n=288)$ in group 3 $(P<.0001)$. Patients who received vancomycin alone, in combination with another agent, or another antibiotic therapy decreased from $31 \%(n=123)$ and $29 \%(n=117)$ in groups 1 and 2 to $26 \%(n=119)$ in group 3 . Likewise, the proportion of patients who failed to receive any effective antibiotic therapy (either not treated with antibiotics or received antibiotics without any staphylococcal coverage) decreased from $6 \%(\mathrm{n}=24)$ in group 1 to $2.6 \%(n=12)$ in group 3 .

\section{Temporal Changes in 30-Day Mortality}

There was a trend toward decline in all-cause 30-day mortality for S. aureus BSIs, from $21 \%(\mathrm{n}=153 / 714$, group $1 ; \mathrm{n}=140 / 678$, group 2) mortality in group 1 (2007-2009) and group 2 (2010$2012)$ to $18 \%$ mortality in the group $3(2013-2015 ; P=.06$; Table 2). This decline was driven by a significant decrease in MSSA mortality from $18 \%$ in both group 1 and group 2 to $13 \%$ in group $3(P=.02$; Table 3$)$. In contrast, there was no significant change in 30-day mortality for MRSA infections, with $25 \%$ mortality in group $1(2007-2009 ; n=81 / 318)$ and group $2(2010-2012 ; \mathrm{n}=68 / 276)$ periods and $26 \%(\mathrm{n}=72 / 281)$ in the group 3 (2013-2015) period (Table 2).

\section{Predictors of Mortality}

In univariate analysis, predictors of 30-day mortality for the entire SAB cohort, as well as the MSSA and MRSA cohorts, included age $\geq 65$ years, female gender, $P B S \geq 4$, Charlson score $\geq 3$, and HO infection (Tables 3 and 4). Methicillin resistance was also a significant predictor of 30-day mortality in the univariate analysis in the SAB cohort. Infection with spa-CC008/ST8 or spa-CC002/ST5 genotypes vs non-ST8/ST5 genotypes was associated with higher mortality in the overall SAB cohort but not in the individual MSSA and MRSA cohorts. Additionally, in MSSA infection, malignancy was a predictor of mortality, while Human immunodeficiency virus/AIDS appeared protective. In MRSA infection, in addition to the above variables, use of chemotherapy was a predictor of mortality. A higher vancomycin MIC was not a significant predictor of mortality for either the overall or MSSA and MRSA cohorts. For the MSSA bacteremia group, patients who received targeted AST with cefazolin or oxacillin $\leq 7$ days of a positive index culture had a significantly lower 30-day mortality.

In the adjusted analyses for the SAB cohort, age $\geq 65$ years, female gender, $\mathrm{PBS} \geq 4$, Charlson score $\geq 3$, $\mathrm{HO}$ infection, and chemotherapy remained significant predictors of all-cause 30-day mortality (Table 4 ). For both MRSA and MSSA, age $\geq 65$ years, $\mathrm{PBS} \geq 4$, Charlson score $\geq 3$, and $\mathrm{HO}$ infection were predictors of mortality in the multivariate model. In the MRSA cohort, in addition to the above variables, female gender and use of chemotherapy remained significant predictors. In MSSA infection, 


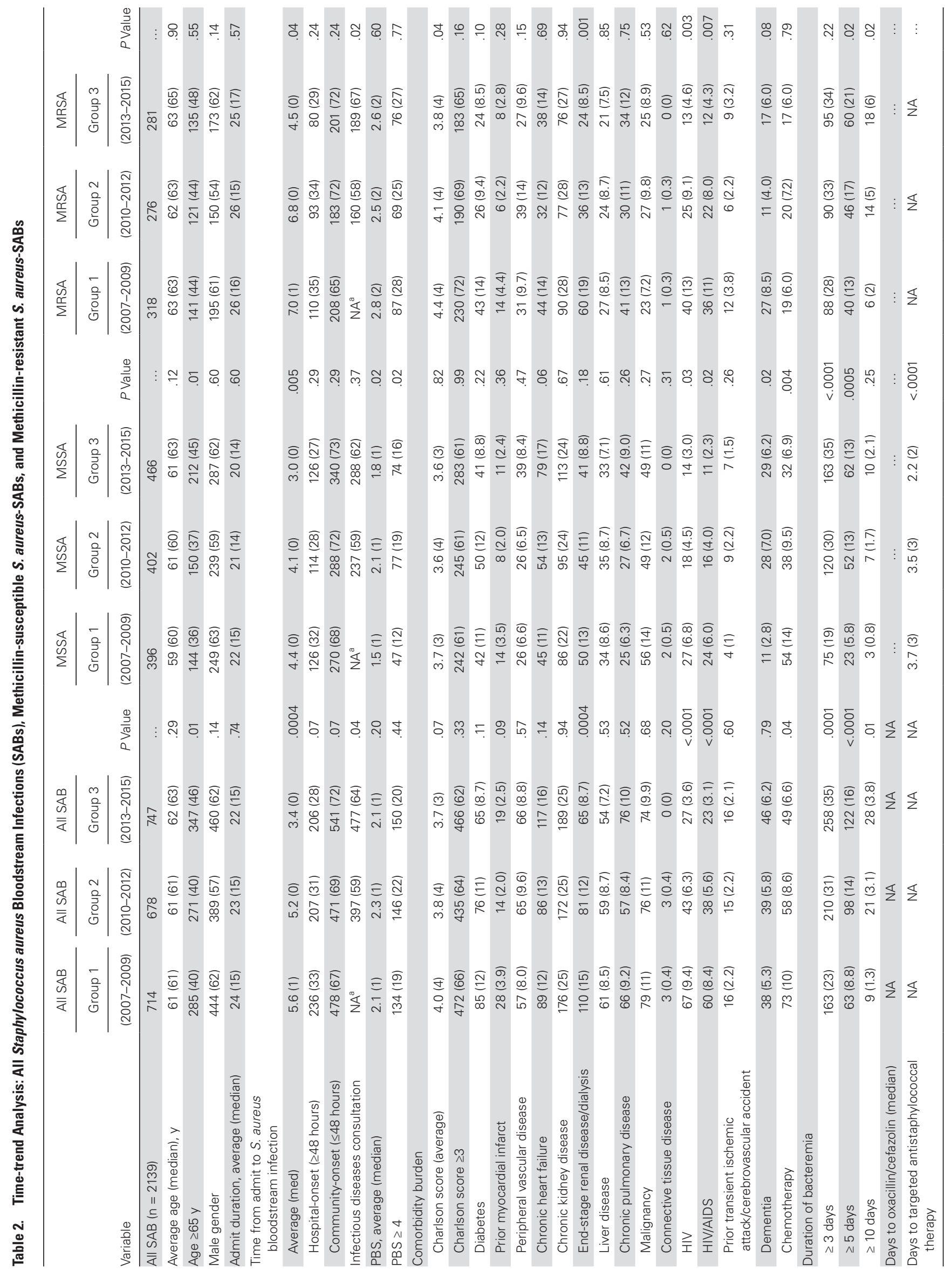




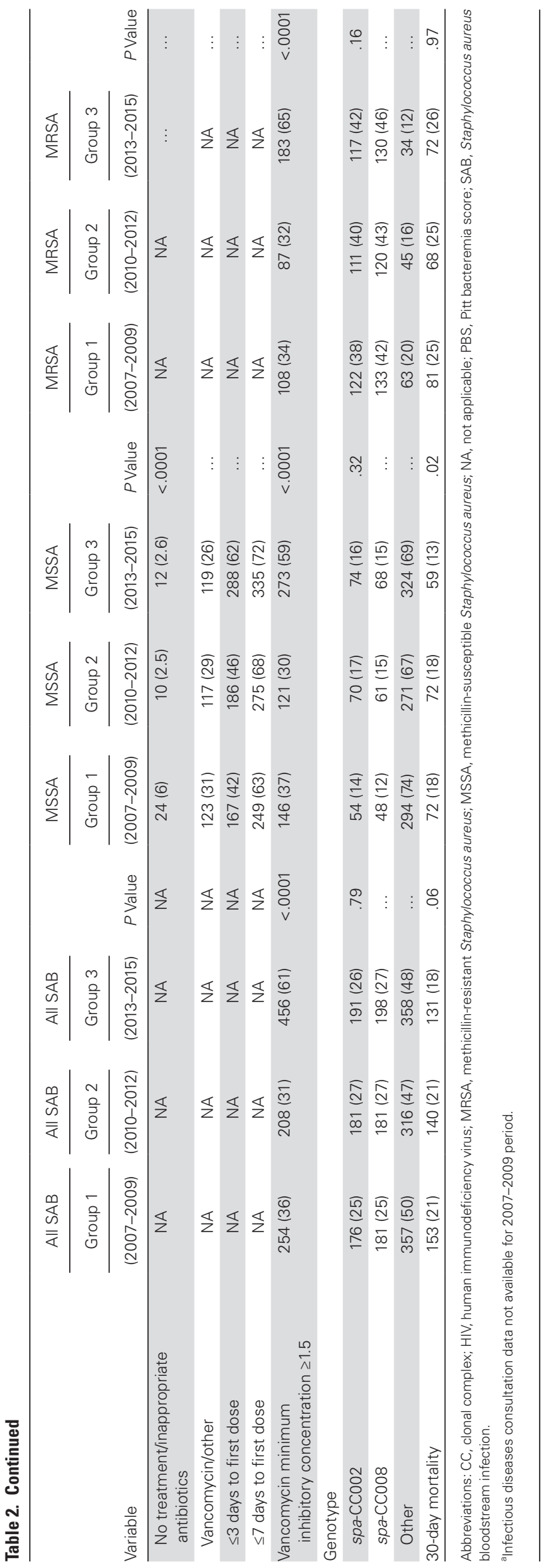

treatment with targeted AST within 7 days of the index culture was significantly associated with survival.

\section{DISCUSSION}

In this retrospective cohort study of $S$. aureus bloodstream infections at a large academic medical center during a 9-year period, we found a significant decrease in mortality for MSSA bacteremia cases, corresponding with a significant decrease in the time to targeted AST (cefazolin or oxacillin). This mortality trend in MSSA infection occurred in the setting of stable variables such as average age, gender, comorbidity burden, and bacterial genotypes. Furthermore, mortality in MSSA infections decreased, despite an increasing proportion of patients aged $\geq 65$ years with PBS $\geq 4$ and longer bacteremia episodes, variables typically associated with increased mortality. In contrast, 30-day mortality rates for MRSA remained high and did not significantly change during the study.

Underlying the observed decrease in time to AST for MSSA cases, in 2011 our medical center adopted rapid diagnostic testing for methicillin resistance through PBP2a agglutination testing, and in 2014, rapid organism identification through Cepheid GeneXpert/Biofire was implemented. Providers were notified by phone by the Microbiology Lab with identification of MSSA or MRSA in blood cultures. The PBP2a test shortened the time between blood culture collection and pathogen identification and susceptibility compared with prior routine culturing techniques. Along with this change, there was a corresponding effort in antimicrobial stewardship and an emphasis on narrowing antibiotic coverage when indicated.

As the proportion of MSSA-associated BSI is rising in some settings, there has been increasing focus on the impact of rapid susceptibility identification to enable earlier adjustment in therapy [9, 22-24]. Early tailoring of antibiotics from vancomycin to targeted therapy (usually an antistaphylococcal penicillin, such as nafcillin or oxacillin, or cefazolin) has been shown to improve outcomes in MSSA SAB and reduce complications, such as nephrotoxicity and persistent bacteremia [24, 25]. Some studies have shown improvements in mortality comparing betalactams to vancomycin alone as definitive therapy and potentially further mortality benefit with use of cefazolin or targeted AST as definitive therapy [25-28]. Currently there is debate over the best choice of targeted antistaphylococcal treatment [29-31]. Our study did not compare outcomes by different AST choices, but this remains an important area of inquiry.

The association between mortality and decreased time to targeted AST was not necessarily causal and may signal other changes in medical care, such as improvement in care processes including earlier ID consultation and echocardiography in endocarditis, that have been shown to significantly improve mortality outcomes in SAB $[32,33]$. While there were no significant shifts in demographic categories, such as average age, gender, $\mathrm{CO}$ vs $\mathrm{HO}$ status, and overall comorbidity burden, there also

Reduced S. aureus Bacteremia Mortality • CID 2020:70 (15 April) • 1671 


\begin{tabular}{|c|c|c|c|c|}
\hline \multirow[b]{2}{*}{ Variable at Bacteremia Onset } & \multicolumn{2}{|c|}{ Univariate } & \multicolumn{2}{|c|}{ Multivariate } \\
\hline & OR $(95 \% \mathrm{Cl})$ & $P$ Value & OR $(95 \% \mathrm{Cl})$ & $P$ Value \\
\hline Age $>65 y$ & $2.9(2.3-3.6)$ & $<.0001$ & $1.7(1.2-2.2)$ & .001 \\
\hline Female gender & $1.6(1.3-1.9)$ & $<.0001$ & $1.6(1.3-2.0)$ & .0002 \\
\hline \multicolumn{5}{|l|}{$\mathrm{CO}$ vs $\mathrm{HO}$} \\
\hline $\mathrm{CO}$ & $0.6(0.5-0.8)$ & $<.0001$ & $\ldots$ & $\ldots$ \\
\hline $\mathrm{HO}$ & $1.6(1.3-2.1)$ & $<.0001$ & $1.5(1.2-2.0)$ & .0007 \\
\hline Infectious diseases consultation & $0.86(0.63-1.19)$ & .33 & $\ldots$ & \\
\hline Pitt bacteremia score $\geq 4$ & $7.3(5.7-9.2)$ & $<.0001$ & $6.6(5.1-8.6)$ & $<.0001$ \\
\hline \multicolumn{5}{|l|}{ Comorbidity burden } \\
\hline Charlson score $\geq 3$ & $2.7(2.1-3.5)$ & $<.0001$ & $2.1(1.4-3.0)$ & .0001 \\
\hline Diabetes & $0.7(0.5-1.0)$ & .06 & $0.7(0.4-1.1)$ & NS \\
\hline Prior myocardial infarct & $1.6(0.9-2.8)$ & .11 & $1.0(0.5-1.9)$ & NS \\
\hline Peripheral vascular disease & $1.0(0.7-1.5)$ & .89 & & $\ldots$ \\
\hline Chronic heart failure & $1.2(0.9-1.7)$ & .15 & $1.0(0.7-1.5)$ & NS \\
\hline Chronic kidney disease & $0.9(0.7-1.2)$ & .50 & & $\ldots$ \\
\hline End-stage renal disease/dialysis & $0.8(0.6-1.1)$ & .19 & $0.9(0.6-1.3)$ & NS \\
\hline Liver disease & $1.0(0.7-1.5)$ & .92 & $\ldots$ & $\ldots$ \\
\hline Chronic pulmonary disease & $1.0(0.7-1.4)$ & .79 & $\ldots$ & $\ldots$ \\
\hline Malignancy & $1.5(1.1-2.1)$ & .01 & $1.1(0.7-1.7)$ & NS \\
\hline Connective tissue disease & $0.8(0.1-6.9)$ & .84 & $\ldots$ & $\ldots$ \\
\hline HIV & $0.5(0.3-0.8)$ & .008 & $\ldots$ & $\ldots$ \\
\hline HIV/AIDS & $0.5(0.3-0.9)$ & .02 & $0.6(0.3-1.3)$ & NS \\
\hline Prior transient ischemic attack/cerebrovascular accident & $3.7(1.4-9.5)$ & .008 & $1.7(0.6-5.2)$ & NS \\
\hline Dementia & $0.9(0.6-1.5)$ & .75 & $\ldots$ & $\ldots$ \\
\hline Chemotherapy & $1.6(1.1-2.2)$ & .01 & $1.9(1.2-2.9)$ & .007 \\
\hline \multicolumn{5}{|l|}{ Bacteremia duration } \\
\hline$\geq 3$ days & $1.0(0.8-1.3)$ & .92 & $\ldots$ & $\ldots$ \\
\hline$\geq 5$ days & $1.1(0.8-1.5)$ & .65 & $\ldots$ & $\ldots$ \\
\hline$\geq 10$ days & $0.7(0.4-1.5)$ & .41 & $\ldots$ & $\ldots$ \\
\hline \multicolumn{5}{|l|}{ Antimicrobial resistance } \\
\hline Methicillin resistance & $1.8(1.4-2.2)$ & $<.0001$ & $1.3(1.0-1.8)$ & NS \\
\hline Vancomycin minimum inhibitory concentration $\geq 1.5$ & $1.0(0.80-1.2)$ & .75 & $\ldots$ & $\ldots$ \\
\hline \multicolumn{5}{|l|}{ Genotype } \\
\hline spa-CC008/ST8 vs. other & $1.4(1.1-1.8)$ & $<.0001$ & $1.1(0.8-1.5)$ & NS \\
\hline spa-CC002/ST5 vs. other & $1.8(1.4-2.3)$ & $<.0001$ & $1.1(0.8-1.6)$ & NS \\
\hline Other (non-CC002/CC008) & Ref & $\ldots$ & $\ldots$ & $\ldots$ \\
\hline
\end{tabular}

Abbreviations: CC, clonal complex; $\mathrm{Cl}$, confidence interval; $\mathrm{CO}$, community-onset; HIV, human immunodeficiency virus; $\mathrm{HO}$, hospital-onset; $\mathrm{NS}$, not significant; OR, odds ratio.

may have been other changes in the patient population or clinical features (such as source of infection).

Surprisingly, the distribution of bacterial genotypes by spa-CC did not change significantly over the 9 -year study period. This stability of strain background is in contrast to what has been seen at other centers and geographic locations [34]. spa-CC008 was a dominant CC in not only the MRSA infections but also MSSA cases in our study. The most notable member of spa-CC008 in MRSA is the pandemic clone USA300, which causes most community-associated and, increasingly, hospitalassociated MRSA infections in the United States [35, 36]. MSSA infections are typically caused by a diverse group of genotypes [37]; however, spa-CC008 represented a significant proportion of MSSA infectious strains overall and throughout the study. Genotypes did not significantly predict mortality, consistent with findings from other studies $[4,38]$. The proportion of isolates with vancomycin MIC $\geq 1.5$ also increased across the $\mathrm{SAB}$ cohort study period; however, it was not a predictor of mortality for either MSSA or MRSA infections. Other studies have shown a similar lack of correlation between vancomycin MIC and mortality, although there is controversy over whether elevated MIC for non-vancomycin-intermediate S. aureus strains is associated with other poor outcomes, such as endocarditis and metastatic seeding $[39,40]$. One limitation of the MIC data is that they were determined using MicroScan rather than the E-test, potentially leading to less-accurate MIC quantification.

Limitations of this study include that it occurred at a single study site and geographic location, perhaps not fully reflecting microbiologic and clinical patterns elsewhere. There was also a lack of information about infective source, such as pneumonia, and of 


\begin{tabular}{|c|c|c|c|c|c|c|c|c|}
\hline \multirow[b]{3}{*}{ Variable } & \multicolumn{4}{|c|}{ MSSA } & \multicolumn{4}{|c|}{ MRSA } \\
\hline & \multicolumn{2}{|c|}{ Univariate } & \multicolumn{2}{|c|}{ Multivariate } & \multicolumn{2}{|c|}{ Univariate } & \multicolumn{2}{|c|}{ Multivariate } \\
\hline & OR $(95 \% \mathrm{Cl})$ & $P$ Value & OR $(95 \% \mathrm{Cl})$ & $P$ Value & OR $(95 \% \mathrm{Cl})$ & $P$ Value & OR $(95 \% \mathrm{Cl})$ & $P$ Value \\
\hline Age $>65 y$ & $2.9(2.1-3.9)$ & $<.0001$ & $1.8(1.2-2.7)$ & .006 & $2.7(2.0-3.8)$ & $<.0001$ & $1.7(1.1-2.7)$ & .02 \\
\hline Female gender & $1.6(1.2-2.1)$ & .004 & $1.4(1.0-1.9)$ & NS & $1.5(1.1-2.1)$ & .008 & $1.7(1.2-2.4)$ & .004 \\
\hline \multicolumn{9}{|l|}{$\mathrm{CO}$ vs $\mathrm{HO}$} \\
\hline $\mathrm{CO}$ & $0.6(0.4-0.8)$ & .001 & $\ldots$ & & $0.6(0.5-0.9)$ & .006 & & $\ldots$ \\
\hline $\mathrm{HO}$ & $1.7(1.2-2.3)$ & .001 & $1.6(1.1-2.3)$ & .02 & $1.6(1.1-2.1)$ & .006 & $1.5(1.0-2.1)$ & .03 \\
\hline Infectious diseases consultation & $0.75(0.5-1.12)$ & .19 & $0.8(0.5-1.3)$ & .4 & $1.0(0.6-1.6)$ & .89 & & $\ldots$ \\
\hline Pitt bacteremia score $\geq 4$ & $7.9(5.6-11.1)$ & $<.0001$ & $6.7(4.6-9.7)$ & $<.0001$ & $6.1(4.4-8.6)$ & $<.0001$ & $6.3(4.4-9.0)$ & $<.0001$ \\
\hline \multicolumn{9}{|l|}{ Comorbidity burden } \\
\hline Charlson score $\geq 3$ & $2.8(1.9-3.9)$ & $<.0001$ & $1.9(1.2-3.1)$ & .007 & $2.5(1.7-3.6)$ & $<.0001$ & $1.8(1.1-3.1)$ & .03 \\
\hline Diabetes & $0.7(0.4-1.3)$ & .28 & $\ldots$ & & $0.6(0.4-1.1)$ & .10 & $0.7(0.4-1.3)$ & NS \\
\hline Prior myocardial infarct & $1.2(0.5-2.9)$ & .74 & $\ldots$ & & $2.0(0.9-4.3)$ & .09 & $1.5(0.6-3.6)$ & NS \\
\hline Peripheral vascular disease & $1.0(0.6-1.8)$ & .91 & $\ldots$ & . & $0.9(0.6-1.5)$ & .71 & & $\ldots$ \\
\hline Chronic heart failure & $1.1(0.7-1.7)$ & .60 & $\ldots$ & $\ldots$ & $1.4(0.9-2.2)$ & .10 & $1.3(0.8-2.2)$ & NS \\
\hline Chronic kidney disease & $1.0(0.7-1.4)$ & .83 & $\ldots$ & . & $0.8(0.6-1.2)$ & .27 & .. & $\ldots$ \\
\hline End-stage renal disease/dialysis & $0.8(0.5-1.3)$ & .34 & $\ldots$ & & $0.8(0.5-1.2)$ & .23 & . & $\ldots$ \\
\hline Liver disease & $1.0(0.6-1.7)$ & .92 & $\ldots$ & & $1.1(0.6-1.8)$ & .82 & .. & $\ldots$ \\
\hline Chronic pulmonary disease & $0.6(0.3-1.2)$ & .14 & $0.6(0.3-1.2)$ & NS & $1.1(0.7-1.7)$ & .72 & .. & $\ldots$ \\
\hline Malignancy & $1.8(1.2-2.7)$ & .004 & $1.6(0.9-2.8)$ & NS & $1.3(0.8-2.3)$ & .26 & .. & $\ldots$ \\
\hline Connective Tissue Disease & $0.0(0.0)$ & .98 & $\ldots$ & & $3.0(0.2-47)$ & .44 & . & $\ldots$ \\
\hline HIV & $0.2(0.04-0.7)$ & .02 & $\ldots$ & $\ldots$ & $0.6(0.3-1.1)$ & .07 & .. & \\
\hline HIVIAIDS & $0.2(0.05-0.9)$ & .03 & $0.3(0.1-1.5)$ & NS & $0.6(0.3-1.1)$ & .11 & $0.9(0.4-1.9)$ & NS \\
\hline $\begin{array}{l}\text { Prior transient ischemic attack/ } \\
\text { cerebrovascular accident }\end{array}$ & $1.3(0.4-4.7)$ & .68 & $\ldots$ & $\ldots$ & $3.0(0.96-9.4)$ & .06 & $1.6(0.4-6.1)$ & NS \\
\hline Dementia & $0.7(0.3-1.5)$ & .32 & $\ldots$ & $\ldots$ & $1.1(0.6-2.1)$ & .72 & .. & $\ldots$ \\
\hline Chemotherapy & $1.4(0.9-2.2)$ & .19 & $1.0(0.5-1.8)$ & NS & $2.4(1.4-4.1)$ & .002 & $3.4(1.8-6.2)$ & .0001 \\
\hline \multicolumn{9}{|l|}{ Bacteremia duration } \\
\hline$\geq 3$ days & $1.0(0.7-1.4)$ & .93 & $\ldots$ & $\ldots$ & $1.0(0.7-1.4)$ & .99 & $\ldots$ & \\
\hline$\geq 5$ days & $1.1(0.7-1.7)$ & .81 & $\ldots$ & $\ldots$ & $1.0(0.6-1.5)$ & .86 & $\ldots$ & $\ldots$ \\
\hline$\geq 10$ Days & $0.6(0.1-2.5)$ & .46 & $\ldots$ & $\ldots$ & $0.7(0.3-1.5)$ & .33 & $\ldots$ & $\ldots$ \\
\hline Targeted AST $\leq 7$ days & $0.3(0.2-0.4)$ & $<.0001$ & $0.4(0.3-0.6)$ & $<.0001$ & NA & NA & $\ldots$ & $\ldots$ \\
\hline $\begin{array}{l}\text { Vancomycin minimum inhibitory } \\
\text { concentration } \geq 1.5\end{array}$ & $1.0(0.7-1.3)$ & .9 & $\ldots$ & $\ldots$ & $0.9(0.7-1.3)$ & .70 & $\ldots$ & \\
\hline \multicolumn{9}{|l|}{ Genotype } \\
\hline spa-CC008/ST8 vs other & $1.2(0.8-1.8)$ & .5 & $1.3(0.8-2.1)$ & NS & $1.0(0.6-1.5)$ & .90 & $\ldots$ & \\
\hline spa-CC002/ST5 vs other & $1.4(1.0-2.1)$ & .07 & $1.1(0.7-1.7)$ & NS & $1.3(0.9-2.1)$ & .21 & & $\ldots$ \\
\hline Other (non-CC002/CC008) & Ref & Ref & & $\ldots$ & Ref & Ref & $\ldots$ & \\
\hline
\end{tabular}

Abbreviations: CC, clonal complex; Cl, confidence interval; CO, community onset; HIV, human immunodeficiency virus; HO, hospital onset; MRSA, methicillin-resistant Staphylococcus aureus; MSSA, methicillin-susceptible Staphylococcus aureus; OR, odds ratio.

infectious complications, such as endocarditis and secondary metastatic seeding of infection. Complications such as endocarditis and metastatic seeding are known to increase mortality in SAB. Changes in rates of such complications over time (ie, a decrease in rates of endocarditis) could have contributed to the mortality trends. Unmeasured bacterial factors may have also influenced mortality but were not captured by our genotyping approach.

Our study of a large SAB cohort spanning 9 years showed a substantial decrease in mortality in invasive MSSA bacteremia, corresponding to a narrowing of the time to targeted AST. It is likely that other factors, such as rapid organism identification and susceptibility data, have contributed to the improved outcomes. Our results emphasize the potential for significant mortality reduction in SAB when hospitals implement early diagnostic techniques and antibiotic stewardship efforts.

\section{Notes}

Author contributions. A.-C. U. and E. D. A. had full access to all of the data in the study and take responsibility for the integrity of the data and the accuracy of the data analysis.

Financial support. This work was supported in part by the National Institutes of Health (grants K08AI090013, to A.-C. U., and 5T32AI10085202, to E. D. A.) and the Columbia University Irving Scholarship (to A.-C. U.).

Potential conflicts of interest. A.-C. U. has received research funding unrelated to the current study from Merck, GlaxoSmithKline (GSK), and Allergan. F. D. L. and N. M. have received research funding from GSK. All other authors report no potential conflicts. All authors have submitted the ICMJE Form for 
Disclosure of Potential Conflicts of Interest. Conflicts that the editors consider relevant to the content of the manuscript have been disclosed.

\section{References}

1. Cosgrove SE, Sakoulas G, Perencevich EN, Schwaber MJ, Karchmer AW, Carmeli Y. Comparison of mortality associated with methicillin-resistant and methicillin-susceptible Staphylococcus aureus bacteremia: a meta-analysis. Clin Infect Dis 2003; 36:53-9.

2. Lowy FD. Staphylococcus aureus infections. N Engl J Med 1998; 339:520-32.

3. McClelland RS, Fowler VG Jr, Sanders LL, et al. Staphylococcus aureus bacteremia among elderly vs younger adult patients: comparison of clinical features and mortality. Arch Intern Med 1999; 159:1244-7.

4. Recker M, Laabei M, Toleman MS, et al. Clonal differences in Staphylococcus aureus bacteraemia-associated mortality. Nat Microbiol 2017; 2:1381-8.

5. Park KH, Greenwood-Quaintance KE, Uhl JR, et al. Molecular epidemiology of Staphylococcus aureus bacteremia in a single large Minnesota medical center in 2015 as assessed using MLST, core genome MLST and spa typing. PLoS One 2017; $12: \mathrm{e} 0179003$.

6. David MZ, Boyle-Vavra S, Zychowski DL, Daum RS. Methicillin-susceptible Staphylococcus aureus as a predominantly healthcare-associated pathogen: a possible reversal of roles? PLoS One 2011; 6:e18217.

7. David MZ, Cadilla A, Boyle-Vavra S, Daum RS. Replacement of HA-MRSA by CA-MRSA infections at an academic medical center in the midwestern United States, 2004-5 to 2008. PLoS One 2014; 9:e92760.

8. David MZ, Daum RS, Bayer AS, et al. Staphylococcus aureus bacteremia at 5 US academic medical centers, 2008-2011: significant geographic variation in community-onset infections. Clin Infect Dis 2014; 59:798-807.

9. Jokinen E, Laine J, Huttunen R, et al. Trends in incidence and resistance patterns of Staphylococcus aureus bacteremia. Infect Dis (Lond) 2018; 50:52-8.

10. Cosgrove SE, Qi Y, Kaye KS, Harbarth S, Karchmer AW, Carmeli Y. The impact of methicillin resistance in Staphylococcus aureus bacteremia on patient outcomes: mortality, length of stay, and hospital charges. Infect Control Hosp Epidemiol $2005 ; 26: 166-74$

11. Yaw LK, Robinson JO, Ho KM. A comparison of long-term outcomes after methicillin-resistant and methicillin-sensitive Staphylococcus aureus bacteraemia: an observational cohort study. Lancet Infect Dis 2014; 14:967-75.

12. Kaasch AJ, Barlow G, Edgeworth JD, et al; ISAC, INSTINCT, SABG, UKCIRG and Colleagues. Staphylococcus aureus bloodstream infection: a pooled analysis of five prospective, observational studies. J Infect 2014; 68:242-51.

13. Khatib R, Sharma M, Iyer S, et al. Decreasing incidence of Staphylococcus aureus bacteremia over 9 years: greatest decline in community-associated methicillinsusceptible and hospital-acquired methicillin-resistant isolates. Am J Infect Control 2013; 41:210-3

14. Bassetti M, Peghin M, Trecarichi EM, et al. Characteristics of Staphylococcus aureus bacteraemia and predictors of early and late mortality. PLoS One 2017; 12:e0170236.

15. Hansen MU, Gotland N, Mejer N, Petersen A, Larsen AR, Benfield T; Danish Staphylococcal Bacteremia Study Group. Diabetes increases the risk of disease and death due to Staphylococcus aureus bacteremia. A matched case-control and cohort study. Infect Dis (Lond) 2017; 49:689-97.

16. Smit J, López-Cortés LE, Kaasch AJ, et al. Gender differences in the outcome of community-acquired Staphylococcus aureus bacteraemia: a historical populationbased cohort study. Clin Microbiol Infect 2017; 23:27-32.

17. Smit J. Community-acquired Staphylococcus aureus bacteremia: studies of risk and prognosis with special attention to diabetes mellitus and chronic heart failure. Dan Med J 2017; 64:B5379.

18. Guillamet MCV, Vazquez R, Deaton B, Shroba J, Vazquez L, Mercier RC Host-pathogen-treatment triad: host factors matter most in MRSA bacteremia outcomes. Antimicrob Agents Chemother 2018; 62:e1902-17.

19. Clinical and Laboratory Standards Institute. Performance standards for antimicrobial susceptibility testing. Wayne, PA: CLSI, 2015

20. Shopsin B, Gomez M, Montgomery SO, et al. Evaluation of protein A gene polymorphic region DNA sequencing for typing of Staphylococcus aureus strains. J Clin Microbiol 1999; 37:3556-63.

21. O'Hara FP, Suaya JA, Ray GT, et al. spa typing and multilocus sequence typing show comparable performance in a macroepidemiologic study of Staphylococcus aureus in the United States. Microb Drug Resist 2016; 22:88-96.
22. Smith JR, Frens JJ, Snider CB, Claeys KC. Impact of a pharmacist-driven care package on Staphylococcus aureus bacteremia management in a large community healthcare network: a propensity score-matched, quasi-experimental study. Diagn Microbiol Infect Dis 2018; 90:50-4.

23. Romero-Gómez MP, Cendejas-Bueno E, García Rodriguez J, Mingorance J. Impact of rapid diagnosis of Staphylococcus aureus bacteremia from positive blood cultures on patient management. Eur J Clin Microbiol Infect Dis 2017; 36:2469-73.

24. Eby JC, Richey MM, Platts-Mills JA, Mathers AJ, Novicoff WM, Cox HL. A healthcare improvement intervention combining nucleic acid microarray testing with direct physician response for management of Staphylococcus aureus bacteremia. Clin Infect Dis 2018; 66:64-71.

25. Schweizer ML, Furuno JP, Harris AD, et al. Comparative effectiveness of nafcillin or cefazolin versus vancomycin in methicillin-susceptible Staphylococcus aureus bacteremia. BMC Infect Dis 2011; 11:279.

26. Sakoulas G, Geriak M, Nizet V. Is a reported penicillin allergy sufficient grounds to forgo the multidimensional antimicrobial benefits of beta-lactam antibiotics? Clin Infect Dis 2019; 68:157-64.

27. McDanel JS, Perencevich EN, Diekema DI, et al. Comparative effectivenes of beta-lactams versus vancomycin for treatment of methicillin-susceptible Staphylococcus aureus bloodstream infections among 122 hospitals. Clin Infect Dis 2015; 61:361-7.

28. Kim SH, Kim KH, Kim HB, et al. Outcome of vancomycin treatment in patients with methicillin-susceptible Staphylococcus aureus bacteremia. Antimicrob Agents Chemother 2008; 52:192-7.

29. McDanel JS, Roghmann MC, Perencevich EN, et al. Comparative effectiveness of cefazolin versus nafcillin or oxacillin for treatment of methicillin-susceptible Staphylococcus aureus infections complicated by bacteremia: a nationwide cohort study. Clin Infect Dis 2017; 65:100-6.

30. Pollett S, Baxi SM, Rutherford GW, Doernberg SB, Bacchetti P, Chambers HF Cefazolin versus nafcillin for methicillin-sensitive Staphylococcus aureus bloodstream infection in a California tertiary medical center. Antimicrob Agents Chemother 2016; 60:4684-9.

31. Li J, Echevarria KL, Hughes DW, Cadena JA, Bowling JE, Lewis JS 2nd. Comparison of cefazolin versus oxacillin for treatment of complicated bacteremia caused by methicillin-susceptible Staphylococcus aureus. Antimicrob Agents Chemother 2014; 58:5117-24.

32. Lee BJ, Rao SN, Wang SK, et al. Implementation of a cefazolin-based stewardship pathway for methicillin-susceptible Staphylococcus aureus bloodstream infections paired with infectious diseases consultation. Int J Antimicrob Agents 2017; 49:650-4.

33. Goto M, Perencevich EN, Ohl ME. Immortal time bias in assessing evidence-based care processes for Staphylococcus aureus bacteremia-reply. JAMA Intern Med 2018; 178:296.

34. Knight GM, Budd EL, Whitney L, et al. Shift in dominant hospital-associated methicillin-resistant Staphylococcus aureus (HA-MRSA) clones over time. J Antimicrob Chemother 2012; 67:2514-22.

35. Carrel M, Perencevich EN, David MZ. USA300 methicillin-resistant Staphylococcus aureus, United States, 2000-2013. Emerg Infect Dis 2015; 21:1973-80.

36. Diekema DJ, Richter SS, Heilmann KP, et al. Continued emergence of USA300 methicillin-resistant Staphylococcus aureus in the United States: results from a nationwide surveillance study. Infect Control Hosp Epidemiol 2014; 35:285-92.

37. Miko BA, Hafer CA, Lee CJ, et al. Molecular characterization of methicillinsusceptible Staphylococcus aureus clinical isolates in the United States, 2004 to 2010. J Clin Microbiol 2013; 51:874-9.

38. Gasch O, Camoez M, Dominguez MA, et al; REIPI/GEIM Study Groups. Lack of association between genotypes and haematogenous seeding infections in a large cohort of patients with methicillin-resistant Staphylococcus aureus bacteraemia from 21 Spanish hospitals. Clin Microbiol Infect 2014; 20:361-7.

39. Fernández-Hidalgo N, Ribera A, Larrosa MN, et al. Impact of Staphylococcus aureus phenotype and genotype on the clinical characteristics and outcome of infective endocarditis. a multicentre, longitudinal, prospective, observational study. Clin Microbiol Infect 2018; 24:985-91.

40. Sullivan SB, Austin ED, Stump S, et al. Reduced vancomycin susceptibility of methicillin-susceptible Staphylococcus aureus has no significant impact on mortality but results in an increase in complicated infection. Antimicrob Agents Chemother 2017; 61:e00316-17. 